\title{
Prevalence of folic acid supplement consumption before and during pregnancy, and its determinants among community health center referrals
}

\author{
Neda Ezzeddin', Rosa Zavoshy², Mostafa Noroozi ${ }^{3}$ \\ ${ }^{1}$ Student Research Committee, Faculty of Nutrition Science and Food Technology, Shahid Beheshti University of Medical Sciences, Tehran; ${ }^{2}$ Department \\ of Nutrition, Faculty of Health, ${ }^{3}$ Children Growth Research Center, Qazvin University of Medical Sciences, Qazvin, Iran
}

\section{Objective}

The aim of this study is to assess the prevalence and determinants of folic acid supplementation among women referred to community health centers.

\section{Methods}

This was a cross-sectional study conducted in 325 women referred to community health centers. The subjects were selected from 8 community health centers, using a stratified sampling technique. Data regarding demographics, socioeconomic status, obstetrics, folic acid supplementation status, and household food security status were obtained via questionnaires. The data was analyzed in SPSS v22.

\section{Results}

The prevalence of folic acid supplementation both before and during pregnancy was $54.5 \%$. The results of the study showed that folic acid supplementation had a significant positive association with education level (odds ratio [OR], 0.441; 95\% confidence interval $[\mathrm{Cl}], 0.199-0.977 ; P<0.05)$, being employed $(\mathrm{OR}, 0.353 ; 95 \% \mathrm{Cl}, 0.148-0.840 ; P<0.05)$, and planned pregnancy $(\mathrm{OR}, 18.113 ; 95 \% \mathrm{Cl}, 7.371-44.51 ; P<0.001)$. However, other variables, including age, husband's age, husband's education and employment status, the number of prior pregnancies, economic satisfaction, and household food security, were nonsignificant factors affecting folic acid supplementation.

\section{Conclusion}

Women with lower socioeconomic status are less likely to take folic acid supplements, and more effort should be made to increase their awareness of the importance of supplementation. Unplanned pregnancy is another strong risk factor for not supplementing with folic acid, and thus should be avoided.

Keywords: Folic acid; Contraception; Food security; Economic conditions

\section{Introduction}

Nutritional status plays an important role in the critical period of pregnancy for women and their unborn infants [1]. Pregnant women need more folic acid for the growth and development of the fetus [2]. Folic acid deficiency during pregnancy may lead to health problems in mothers, such as anemia and peripheral neuropathy, and in infants, including congenital abnormalities [2] and neural tube defects (NTDs) [3]. There are various risk factors for NTDs including poor maternal nutritional status and maternal folate deficiency during pregnancy [4]. Supplementation with folic acid has,
Received: 2019.03.12. Revised: 2019.06.03. Accepted: 2019.06.07. Corresponding author: Neda Ezzeddin

Department of Community Nutrition, Faculty of Nutrition Science and Food Technology, Shahid Beheshti University of Medical Sciences, No. 7, Shahid Farahzadi Blvd, Shahid Hafezi St. (Western Arghavan), Ghods Town (west), Tehran 19839-63113, Iran E-mail: Neda.Ezzeddin@sbmu.ac.ir https://orcid.org/0000-0002-0334-0858

Articles published in Obstet Gynecol Sci are open-access, distributed under the terms of the Creative Commons Attribution Non-Commercial License (http://creativecommons. org/licenses/by-nc/3.0/) which permits unrestricted non-commercial use, distribution, and reproduction in any medium, provided the original work is properly cited.

Copyright $\odot 2019$ Korean Society of Obstetrics and Gynecology 


\section{Obstetrics \& Gynecology Science}

Neda Ezzeddin, et al. Folic acid supplementation determinants

therefore, been identified as a factor in decreasing NTDs in infants [5-10]. Implemented as a worldwide policy by the World Health Organization (WHO) in 2006, the daily consumption of $400 \mu \mathrm{g}$ of a folic acid supplement is recommended for women of childbearing age who are planning a pregnancy [11]. Nevertheless, the implementation of this recommendation remains inadequate [12]. The results of studies have shown that the prevalence of folic acid supplementation is often insufficient in the preconception period $[13,14]$. Several factors have been associated with preconception folic acid supplementation, including maternal age [12]; educational status [13]; marital status [1]; employment status [15]; the number of prior pregnancies [12]; income [16]; whether the pregnancy was planned or unplanned [13]; smoking status [17]; and the level of knowledge, attitude, and awareness of the importance of folic acid supplementation before and during pregnancy $[14,17]$. It is necessary to identify the determinants of folic acid supplementation before and during pregnancy in order to increase the prevalence of folic acid supplementation, and thus decrease the negative consequences of folic acid deficiency on maternal and infant health. This study, therefore, aimed to assess the prevalence and determinants of folic acid supplementation before and during pregnancy, among women referred to community health centers in the city of Tehran.

\section{Materials and methods}

This cross-sectional study was carried out in 325 women who had given birth and had been referred to community health centers in western Tehran between March and June 2014.

Subjects were selected from 8 community health centers across 16 areas, using a stratified sampling technique (with each center as a stratum). These selected centers provided suitable distributions of the population and geographic area).
The sample size for each stratum was proportional to population size, and the convenience sampling method was used to select the samples within a center.

Information regarding demographics (age of women and their husbands), socioeconomic status (education level, occupational status, and economic satisfaction score), obstetrics (planned or unplanned pregnancy and the number of prior pregnancies), folic acid supplementation before and during pregnancy, and household food security status was collected via questionnaires. In order to assess the economic satisfaction score, mothers were asked to select a score from 1 to 10 (subjectively) to indicate their satisfaction with their household economic status.

The 18-item US Department of Agriculture (USDA) questionnaire [18] was used for assessing household food security status. The questionnaire was completed by interviewing participants, and was scored by the researchers as follows: responses "most of the time correct" and "sometimes correct" to questions 1 to 3 and 11 to 13; "almost every month" and "some months" to questions 5, 10, and 16; and "yes" to questions 4,6 to 9, 14, 15, 17, and 18 were scored 1; and responses "is not correct," "does not know or avoids," "only once or twice a month," and "no" were scored 0 . The total score was calculated based the number of positive responses, and women were subsequently divided into 4 groups based on the scores: (a) food secure, (b) food insecure without hunger, (c) food insecure with moderate hunger, and (d) food insecure with severe hunger (Table 1) [19]. In order to analyze the data, groups (c) and (d) were combined to compose the food insecure with hunger group. The validity of this questionnaire and its applicability has been previously demonstrated [20].

The data were analyzed in SPSS version 22 (IBM Inc., Chicago, IL, USA). Associations of folic acid supplementation (both before and during pregnancy) with quantitative variables were assessed using logistic regression, and associations with

Table 1. Classification of the Household food security status based on scores

\begin{tabular}{lcc}
\hline \multirow{2}{*}{ Food security status } & \multicolumn{2}{c}{ Number of positive responses } \\
\cline { 2 - 3 } & $\begin{array}{c}\text { Households without children under } \\
\mathbf{1 8} \text { years (total score:10) }\end{array}$ & $\begin{array}{c}\text { Households with children under } \\
\mathbf{1 8} \text { years (total score:18) }\end{array}$ \\
\hline Food secure & $0-2$ & $0-2$ \\
Food insecure without hunger & $3-5$ & $3-7$ \\
Food insecure with moderate hunger & $6-8$ & $8-12$ \\
Food insecure with severe hunger & $9-10$ & $13-18$ \\
\hline
\end{tabular}




\section{Obstetrics \& Gynecology Science}

Vol. 62, No. 6, 2019

qualitative variables were assessed using the $\chi^{2}$ test. Finally, all variables were assessed in a logistic regression model to determine predictors of folic acid supplementation among women. A value of $P<0.05$ was considered significant.

\section{Results}

In this study, the majority of women were homemakers (86.5\%), had earned a high-school diploma or higher $(78.2 \%)$, were food secure $(65.8 \%)$, and had a planned pregnancy $(79.4 \%)$ (Table 2). The results showed that 182
(56\%) and 302 (92.9\%) of the women had taken folic acid supplements before and during pregnancy respectively (for at least 1 month). However, only 177 (54.5\%) of the women had taken folic acid supplements before pregnancy and continued to supplement during pregnancy (for at least 1 month). The associations between supplementation and the age of the woman, and between supplementation and the age of the husband, were assessed via logistic regression, and these results were not statistically significant (Table 3). The results also did not show any significant association between economic satisfaction scores and folic acid supplementation (Table 3). Logistic regression showed a significant

Table 2. The association of folic acid supplementation with qualitative variables

\begin{tabular}{|c|c|c|c|c|c|c|}
\hline \multirow{2}{*}{ Variables } & \multicolumn{3}{|c|}{ Folic acid supplementation } & \multirow{2}{*}{ OR } & \multirow{2}{*}{$95 \% \mathrm{Cl}$} & \multirow{2}{*}{$P$-value ${ }^{b)}$} \\
\hline & Yes & No & Total & & & \\
\hline Employment status of women & & & & & & $<0.05$ \\
\hline Employment & $30(16.9)$ & $14(9.5)$ & $44(13.5)$ & 1.953 & $0.993-3.841$ & \\
\hline Housekeepers & $147(83.1)$ & $134(90.5)$ & $281(86.5)$ & & & \\
\hline Total & $177(100)$ & $148(100)$ & $325(100)$ & & & \\
\hline Employment status of husbands & & & & & & NS \\
\hline Self-employed & $119(67.6)$ & $100(68.5)$ & $219(68)$ & 0.96 & $0.600-1.538$ & \\
\hline Government employee & $57(32.4)$ & $46(31.5)$ & $103(32)$ & & & \\
\hline Total $^{a)}$ & $176(100)$ & $146(100)$ & $322(100)$ & & & \\
\hline The education levels of women & & & & & & $<0.001$ \\
\hline Under diploma & $24(13.6)$ & $47(31.8)$ & $71(21.8)$ & 2.967 & $1.708-5.153$ & \\
\hline Diploma or higher & $153(86.4)$ & $101(68.2)$ & $254(78.2)$ & & & \\
\hline Total $^{\text {a) }}$ & $177(100)$ & $148(100)$ & $325(100)$ & & & \\
\hline The education levels of husbands & & & & & & $<0.001$ \\
\hline Under diploma & $30(16.9)$ & $53(35.8)$ & $83(25.5)$ & 2.734 & $1.630-4.584$ & \\
\hline Diploma or higher & $147(83.1)$ & $95(64.2)$ & $242(74.5)$ & & & \\
\hline Total & $177(100)$ & $148(100)$ & $325(100)$ & & & \\
\hline Unplanned pregnancy & & & & & & $<0.001$ \\
\hline No & $170(96)$ & $88(59.5)$ & $258(79.4)$ & 0.06 & $0.026-0.138$ & \\
\hline Yes & $7(4)$ & $60(40.5)$ & $67(20.6)$ & & & \\
\hline Total & $177(100)$ & $148(100)$ & $325(100)$ & & & \\
\hline Household Food Security status & & & & & & $<0.05$ \\
\hline Food secure & $131(74)$ & $83(56.1)$ & $214(65.8)$ & - & - & \\
\hline Food insecure without hunger & $26(14.7)$ & $30(20.3)$ & $56(17.2)$ & & & \\
\hline Food insecure with hunger & $20(11.3)$ & $35(23.6)$ & $55(16.9)$ & & & \\
\hline Total & $177(100)$ & $148(100)$ & $325(100)$ & & & \\
\hline
\end{tabular}

Values are presented as number of patients (\%).

$\mathrm{OR}$, odds ratio; $\mathrm{Cl}$, confidence interval; NS, not significant.

a) Missing data $(n=3) ;{ }^{b} \chi^{2}$ test. 


\section{Obstetrics \& Gynecology Science}

Neda Ezzeddin, et al. Folic acid supplementation determinants

association between the number of prior pregnancies and supplementation status (odds ratio, 0.781 ; confidence interval, 0.617-0.989; $P<0.05$ ) (Table 3).

With the $\chi^{2}$ test, the education levels of the women who had taken supplements, and the education levels of their husbands, were found to be significantly higher $(P<0.001)$ (Table 2). Unplanned pregnancy was another strong predictor of folic acid supplementation $(P<0.001)$ (Table 2$)$. The husband's employment status did not play an important role in supplementation status (Table 2). However, the ratio of homemakers to employed women who had taken folic acid supplements was lower $(P<0.05)$ (Table 2$)$. In the current study, household food security status was also assessed in both groups. The $\chi^{2}$ test showed a significant decrease in supplementation with increasing levels of food insecurity $(P<0.05)$ (Table 2).

In logistic regression, after adjustment for variables, only the education $(P<0.05)$ and employment $(P<0.05)$ status of women, along with unplanned pregnancy $(P<0.001)$, were recognized as significant predictors of supplementation status (Table 4).

\section{Discussion}

In this study, the factors affecting folic acid supplementation before and during pregnancy were assessed among women referred to community health centers. Lower education levels (of women), being a homemaker, and unplanned pregnancy were the significant factors associated with the lower supplementation of folic acid, both before and during pregnancy.

The prevalence of women who had taken folic acid supplements for at least 1 month before pregnancy, and continued to supplement into pregnancy, was $54.5 \%$. In a study conducted by Riazi and colleagues [21] in Hamadan, only about $9.6 \%$ of women consumed folic acid supplements before

Table 3. The association of folic acid supplementation with quantitative variables

\begin{tabular}{lcccc}
\hline Variables & SE & OR & 95\% Cl & P-value ${ }^{\text {a) }}$ \\
\hline Women age & 0.020 & 0.993 & $0.955-1.032$ & NS \\
Husbands age & 0.019 & 0.979 & $0.944-1.016$ & NS \\
Economic satisfaction score & 0.063 & 1.128 & $0.996-1.278$ & $0.617-0.989$ \\
Pregnancy number & 0.120 & 0.781 & $<0.05$ \\
\hline
\end{tabular}

SE, standard error; OR, odds ratio; $\mathrm{Cl}$, confidence interval; NS, not significant.

a)Logistic regression.

Table 4. Final logistic regression model for the predictors of folic acid supplementation

\begin{tabular}{|c|c|c|c|c|}
\hline Variables & SE & OR & $95 \% \mathrm{Cl}$ & $P$-value \\
\hline Women age & 0.047 & 0.989 & $0.901-1.085$ & NS \\
\hline Husbands age & 0.044 & 1.015 & 0.932-1.107 & NS \\
\hline The education levels of women & 0.406 & 0.441 & $0.199-0.977$ & $<0.05$ \\
\hline The education levels of husbands & 0.397 & 0.661 & $0.303-1.440$ & NS \\
\hline Employment status of women & 0.443 & 0.353 & $0.148-0.840$ & $<0.05$ \\
\hline Employment status of husband & 0.318 & 0.623 & $0.334-1.162$ & NS \\
\hline Unplanned pregnancy & 0.459 & 18.113 & $7.371-44.510$ & $<0.001$ \\
\hline Pregnancy number & 0.197 & 1.049 & $0.713-1.543$ & NS \\
\hline Economic satisfaction score & 0.079 & 0.942 & 0.808-1.099 & NS \\
\hline \multicolumn{5}{|l|}{ Household food security status } \\
\hline Food secure & - & Reference & - & - \\
\hline Food insecure without hunger & 0.366 & 0.813 & $0.397-1.665$ & NS \\
\hline Food insecure with hunger & 0.397 & 0.747 & $0.343-1.626$ & NS \\
\hline
\end{tabular}

$\mathrm{SE}$, standard error; OR, odds ratio; $\mathrm{Cl}$, confidence interval; NS, not significant. 


\title{
Obstetrics \& Gynecology Science
}

\author{
Vol. 62, No. 6, 2019
}

pregnancy, which was less than what was seen in the current study. In a study by Nosrat et al. [22], 20.12\% of women in Golestan province consumed folic acid supplements during the preconception period. Mashayekhi et al. [14] also reported that about $25.07 \%$ of women in Tabriz consumed folic acid supplements for at least 1 month before pregnancy, and $34.82 \%$ supplemented with folic acid during the first trimester. In a survey of Italian women, De Santis et al. [13] found that $43.4 \%$ of participants took folic acid before becoming pregnant. In the current study, the prevalence of women consuming folic acid supplements was higher before (56\%) and during (92.9\%) pregnancy than in other studies. Although the women's awareness about the importance of consuming folic acid supplements was not directly assessed in the current study, such large differences may indicate an increasing trend in female awareness and knowledge about the importance of folic acid supplementation and its impact on infant health. The difference in geographic areas may be another reason for the large inconsistencies observed.

Socioeconomic status, including women's education level and employment status, were significant determinants of folic acid supplementation. This means that the prevalence of folic acid supplementation was statistically higher in women with higher education levels and who were employed. These findings are consistent with studies by Riazi et al. [21], Roth et al. [15], and De Santis et al. [13]. It has been shown that higher education levels in women can increase their awareness about the necessity of folic acid supplementation, and their understanding of the important period of folic acid supplementation [14,23].

In the current study, economic satisfaction status was assessed subjectively in order to evaluate household economic status, because the participants may have wished to avoid declaring their actual incomes. The results showed higher scores for economic satisfaction in women who consumed folic acid supplements, but this was not statistically significant. In a study conducted by Tamim et al. [17], better economic status was associated with folic acid supplementation. In Iran, community health centers are well distributed across the urban and rural areas of the country in order to provide primary health services for the population. Supplements including iron and folic acid are freely distributed to pregnant women [14], so this may be one reason for the lack of a significant difference in supplementation between women of different economic status.
Food insecurity was another variable evaluated in this study. According to the USDA, food insecurity is defined as, "a household-level economic and social condition of limited or uncertain access to adequate food" [24]. Food insecurity affects dietary quality and quantity of food intake [25]. In a study conducted by Davison et al. [26], food insecurity was associated with poor dietary quality and suboptimal intakes of folate. Since many food-insecure women are undernourished, strategies such as micronutrient supplementation or fortification can be used in order to improve nutritional status [27]. The results of this study showed a decreasing trend in supplementation with increased levels of food insecurity, but this correlation was not found to be statistically significant in logistic regression. This nonsignificant association between food insecurity and supplementation may be due to the free distribution of supplements in community health centers in Iran, as mentioned above. However, food insecure households still need more attention and support.

Although planned pregnancy does not necessarily lead to folic acid supplementation [28], unplanned pregnancy is one of the most important reasons for the lack of folic acid supplementation before pregnancy $[16,29]$. The results of the current study recognized unplanned pregnancy as a robust risk factor affecting supplementation. This finding is consistent with studies by De Santis et al. [13] and Roth et al. [15]. However, planned or unplanned pregnancy was not found to be a significant factor in supplementation among Ethiopian women [30]; which may have been related to low female awareness about the importance of folic acid, lower prescription levels of folic acid, and less education from healthcare providers.

In the current study, the number of prior pregnancies was higher in women who did not use folic acid supplements, but this relationship was not statistically significant. In the study conducted by Dessie et al. [30] of pregnant women in Ethiopia, the number of pregnancies was not an important factor affecting the consumption of folic acid supplements. This finding is also consistent with Rasmussen and Clemmensen's study [23]. On the one hand, in a study conducted by Vitale et al. [16], the number of pregnancies was a negative predictor for supplementation with folic acid, while on the other hand, in a study of Lebanese women by Nasr Hage et al. [12], folic acid intake was significantly associated with a higher number of pregnancies. Based on the different studies, an inconsistency is observed about the association 


\section{Obstetrics \& Gynecology Science}

Neda Ezzeddin, et al. Folic acid supplementation determinants

between the number of prior pregnancies and folic acid supplementation. Perhaps this association varies based on the particular contexts of each study.

Finally, it should be noted that although there was no significant relationship between folic acid supplementation with some variables, we cannot report the lack of association with certainty, as this could be due to the limited sample size.

In the current study, the knowledge, attitude, and awareness of women regarding the importance of consuming folic acid supplements before and during pregnancy, as well as the subsequent consequences to mothers and infants due to not supplementing with folic acid, were not assessed. Future studies with larger sample sizes are recommended to evaluate these factors, and to investigate the impact of folic acid supplementation on birth outcomes.

The current study assessed the prevalence of and factors affecting folic acid supplementation before and during pregnancy, among women referred to community health centers. The results of the study showed that slightly more than half (56\%) of women had taken supplements before pregnancy. Although most women consumed the supplements during pregnancy, because of the importance of having a sufficient folate status before pregnancy, it is essential that supplementation is started before pregnancy, not after pregnancy is confirmed. In this study, several factors affecting supplementation were identified. Lower education levels of women, being a homemaker, and unplanned pregnancy were the significant factors associated with lower supplementation of folic acid both before and during the pregnancy period. Given that women with lower socioeconomic status are more vulnerable to a lack of folic acid supplementation, more efforts should be made to increase the knowledge, attitude, and awareness of women about the importance of supplementation, and the consequences of insufficient supplementation, by community health service staff and the media. Planned pregnancy is another strong factor influencing supplementation. Unplanned pregnancy should therefore be avoided by adopting appropriate policy makers' strategies, including increased education by health center staff and the media.

\section{Acknowledgements}

The authors would like to thank the staff of the community health centers and the women who participated in the study for their kind cooperation.

\section{Conflict of interest}

No potential conflict of interest relevant to this article was reported.

\section{Ethical approval}

The protocol was approved by the Research Council and Ethical Committee of Qazvin University of Medical Sciences, No. D.44.21039. All procedures performed in studies involving human participants were in accordance with the ethical standards of the institutional research committee and with the 1964 Helsinki declaration and its later amendments or comparable ethical standards.

\section{Patient consent}

All participants gave their informed consent to participate in the study.

\section{References}

1. Popa AD, Niță O, Graur Arhire LI, Popescu RM, Botnariu GE, Mihalache L, et al. Nutritional knowledge as a determinant of vitamin and mineral supplementation during pregnancy. BMC Public Health 2013;13:1105.

2. Greenberg JA, Bell SJ, Guan Y, Yu YH. Folic acid supplementation and pregnancy: more than just neural tube defect prevention. Rev Obstet Gynecol 2011;4:52-9.

3. Viswanathan M, Treiman KA, Doto JK, Middleton JC, Coker-Schwimmer EJ, Nicholson WK. Folic acid supplementation: an evidence review for the U.S. Preventive Services Task Force [Internet]. Rockville (MD): Agency for Healthcare Research and Quality (US); 2017 [cited 2018 Dec 16]. Available from: http://www.ncbi.nlm.nih.gov/ books/NBK410113/.

4. Mohammadi N, Mobasheri E, Jafar Golalipour M. Birth prevalence of neural tube defects in Iran: a systematic review. J Pediatr Rev 2018;6:e62091. 


\section{Obstetrics \& Gynecology Science}

Vol. 62, No. 6, 2019

5. MRC Vitamin Study Research Group. Prevention of neural tube defects: results of the Medical Research Council Vitamin Study. Lancet 1991;338:131-7.

6. Tonni G, Centini G, Bonasoni MP, Ventura A, Pattacini P, Cavalli P. Acrania-anencephaly associated with hypospadias. Prenatal ultrasound and MRI diagnosis and molecular folate metabolism pathway analysis. Fetal Pediatr Pathol 2012;31:379-87.

7. Cavalli P, Tonni G, Grosso E, Poggiani C. Effects of inositol supplementation in a cohort of mothers at risk of producing an NTD pregnancy. Birth Defects Res A Clin Mol Teratol 2011;91:962-5.

8. Schmidt RJ, Browne ML, Pessah IN. Caffeine intake and risk of neural tube defects: author response to correspondence. Birth Defects Res A Clin Mol Teratol 2011;91:67-8.

9. Tonni G, Azzoni D, Pizzi C, Bonasoni MP, Cavalli P, Pattacini $P$, et al. Anencephaly-exencephaly sequence and congenital diaphragmatic hernia in a fetus with 46, XX karyotype: early prenatal diagnosis, necropsy, and maternal folate pathway genetic analysis. Fetal Pediatr Pathol 2010;29:69-80.

10. Tonni G, Azzoni D, Panteghini M, Ventura A, Cavalli P. First trimester diagnosis of iniencephaly associated with fetal malformations and trisomy 18: report of a new case and gene analysis on folate metabolism in parents. Congenit Anom (Kyoto) 2007;47:101-4.

11. McStay CL, Prescott SL, Bower C, Palmer DJ. Maternal folic acid supplementation during pregnancy and childhood allergic disease outcomes: a question of timing? Nutrients 2007;9:E123.

12. Nasr Hage C, Jalloul M, Sabbah M, Adib SM. Awareness and intake of folic acid for the prevention of neural tube defects among Lebanese women of childbearing age. Matern Child Health J 2012;16:258-65.

13. De Santis M, Quattrocchi T, Mappa I, Spagnuolo T, Licameli A, Chiaradia $G$, et al. Folic acid use in planned pregnancy: an Italian survey. Matern Child Health J 2013;17:661-6.

14. Mashayekhi SO, Dilmaghanizadeh M, Sattari MR. A survey on the consumption, knowledge and attitude of pregnant women toward the effects of folic acid on pregnancy outcome in Tabriz. Iran J Child Neurol 2011;5:35-42.

15. Roth C, Bjørke-Monsen AL, Reichborn-Kjennerud T,
Nilsen RM, Smith GD, Stoltenberg C, et al. Use of folic acid supplements in early pregnancy in relation to maternal plasma levels in week 18 of pregnancy. Mol Nutr Food Res 2013;57:653-60.

16. Vitale K, Mujkić A, Todorović G, Tulchinsky TH. Is level of knowledge, attitude and use of folic acid among pregnant women in Croatia a call for public health action? Period Biol 2009;111:329-35.

17. Tamim H, Harrison G, Atoui M, Mumtaz G, El-Kak F, Seoud $M$, et al. Preconceptional folic acid supplement use in Lebanon. Public Health Nutr 2009;12:687-92.

18. Rafiei M, Nord M, Sadeghizadeh A, Entezari MH. Assessing the internal validity of a household survey-based food security measure adapted for use in Iran. Nutr J 2009;8:28.

19. Hojaji E, Zavoshy R, Noroozi M, Jahanihashemi H, Ezzedin N. Assessment of household food security and its relationship with some pregnancy complications. Majallahi Danishgahi Ulumi Pizishkii Mazandaran 2015;25:8798.

20. Ramesh T, Dorosty Motlagh AR, Abdollahi M. Prevalence of household food insecurity in the City of Shiraz and its association with socio-economic and demographic factors, 2008. Iran J Nutr Sci Food Technol 2010;4:53-64.

21. Riazi H, Bashirian S, Cheraghi F. Folic acid Intake during preconceptional period. Avicenna J Nurs Midwifery Care 2010;18:38-48.

22. Nosrat SB, Sedehi M, Golalipour MJ. Knowledge and practice of urban Iranian pregnant women towards folic acid intake for neural tube defect prevention. J Pak Med Assoc 2012;62:785-9.

23. Rasmussen MM, Clemmensen D. Folic acid supplementation in pregnant women. Dan Med Bull 2010;57:A4134.

24. Insecurity F. Food insecurity: a public health issue. Public Health Rep 2016;131:655-7.

25. Carmichael SL, Yang W, Herring A, Abrams B, Shaw GM. Maternal food insecurity is associated with increased risk of certain birth defects. J Nutr 2007;137:2087-92.

26. Davison KM, Gondara L, Kaplan BJ. Food insecurity, poor diet quality, and suboptimal intakes of folate and iron are independently associated with perceived mental health in Canadian adults. Nutrients 2017;9:E274.

27. Ramakrishnan U, Lowe A, Vir S, Kumar S, Mohanraj R, Chaturvedi $A$, et al. Public health interventions, barriers, and opportunities for improving maternal nutrition in 


\section{Obstetrics \& Gynecology Science}

Neda Ezzeddin, et al. Folic acid supplementation determinants

India. Food Nutr Bull 2012;33:S71-92.

28. Saxena $V$, Naithani $M$, Kumari $R$, Singh $R$, Das P. Periconceptional supplementation of folic acid-knowledge and practices of pregnant women and health providers. J Family Med Prim Care 2016;5:387-92.

29. Bixenstine PJ, Cheng TL, Cheng D, Connor KA, Mistry KB. Association between preconception counseling and folic acid supplementation before pregnancy and rea- sons for non-use. Matern Child Health J 2015;19:197484.

30. Dessie MA, Zeleke EG, Workie SB, Berihun AW. Folic acid usage and associated factors in the prevention of neural tube defects among pregnant women in Ethiopia: cross-sectional study. BMC Pregnancy Childbirth 2017; 17:313. 